\title{
Resultat av 20 års holkstudier - främst rörande svartvit flugsnappare Ficedula hypoleuca
}

\author{
A 20-year study of a nest-box breeding bird population with special regard to the \\ Pied Flycatcher Ficedula hypoleuca
}

\author{
JAN-ERIC NILSSON
}

\begin{abstract}
Breeding activities in 133 nest-boxes of varying sizes, erected in mainly deciduous woods in Linderås, southeastern Sweden $\left(57^{\circ} 58^{\prime} \mathrm{N} ; 1^{\circ} 15 \mathrm{E}^{\prime}\right)$, were recorded from 1986 to 2005 . In total, 1841 pairs representing 15 species bred in the boxes; mean occupancy was $75 \%$. The Pied Flycatcher Ficedula hypoleuca was the most frequent species. Its population numbers showed no significant trend while its fluctuation pattern largely paralleled those of two contemporary Swedish studies. Dates of spring arrival and start of egg-laying varied independently without any trend. Mean clutch size was 6.32, equalling those obtained in other Swedish studies, even though the pro-

portion of 6-egg clutches and mean number of fledglings (4.26) were significantly lower. Only $40 \%$ of the breeding attempts were entirely without losses, such as failed hatching ( $8 \%$ of 6370 eggs), predation, or usurpation by other species. A total of 550 incubating females and 3653 nestlings were ringed of which $12 \%$ and $0.3 \%$, respectively, returned to the study area in the subsequent season. Of females that returned, $41 \%$ reappeared in the first and $48 \%$ in the second ensuing season.

Jan-Eric Nilsson, Sänninge Brohagen 1, 57397 Tranås. E-mail: brohagen1@glocalnet.net
\end{abstract}

Received 7 January 2008. Accepted 14 February 2008. Editor: S. Svensson

\section{Inledning}

De nedan redovisade studierna är genomförda i Linderås socken, belägen mellan Tranås och Gränna i norra Småland. Ända sedan 1957 har jag haft holkar uppsatta i området - antalet har dock varierat mellan olika perioder och ambitionsnivån vad gäller insamling av häckningsdata har också varierat. Efter att permanent ha flyttat tillbaka till mina gamla hemmamarker beslöt jag att från 1986 utföra mer strukturerade holkstudier, bl.a. inspirerad av ett holkprojekt med många deltagare som vid denna tid leddes från Ekologihuset i Lund och i vilket jag deltog samtliga år.

Det är ett ansenligt faktaunderlag som insamlats under årens lopp. Något egentligt mål hade jag inte med undersökningen när den startade, utan hela projektet byggde dels på den allmänna nyfikenhet på vad som händer i vår fågelfauna, dels på det behov som vi amatörornitologer har av att dokumentera, registrera och jämföra. Hela materialet hade sannolikt hamnat i min bokhylla om jag inte läst en tänkvärd artikel i denna tidskrift (Enemar 1998), där bl.a. just denna problematik diskuterades - det stora avståndet mellan oss amatörer och den veten- skapliga världen, vilket ofta resulterar i att värdefullt material blir kvar i pärmar och byrålådor. Jag tog kontakt med Anders Enemar och han bedömde materialet vara så intressant, att han på ett helt enastående sätt ställde upp som mentor och skickligt ställde sina kunskaper till mitt förfogande och lotsade mig därmed fram till denna artikels tillkomst.

Som framgår nedan är det två arter som helt dominerar beläggningen i de undersökta holkarna, den svartvita flugsnapparen och talgoxen. Förutom en inledande presentation av hela det häckande beståndets numerär och sammansättning under de 20 åren, har jag valt att presentera häckningsdata m.m. endast för den förstnämnda arten. Den svartvita flugsnapparen är sannolikt en av våra mest utforskade fågelarter (se t.ex. Lundberg \& Alatalo 1992). I denna artikel kommer jag dock att i huvudsak begränsa jämförelserna till ett antal liknande svenska långtidsstudier.

\section{Biotopbeskrivning}

Undersökningsområdet präglas av lövskogs- och jordbruksmarker. Inslaget av barrskog får anses som litet, åtminstone med småländska mått mätt. 
De dominerande trädslagen är al, asp, hägg och björk. Men det finns också spridda bestånd av ädellövskog. Stora områden kan betecknas som hagmark och betas av boskap (numera främst köttdjur). Vissa delar är igenvuxna med buskar och mer eller mindre ogenomträngliga snår, vilket bl.a. främjat etableringen av en stabil stam av hasselmus Muscardinus avellanarius. Flera bäckar ("sur-drag") genomkorsar området. Fåglarnas tillgång till naturliga trädhål var inledningsvis god, men har efter senare års avverkningar och stormar minskat. Den mindre hackspetten Dendrocopos minor finns kvar i området, även om beståndet minskar.

\section{Metodbeskrivning}

Under perioden 1986-2000 fanns 133 holkar uppsatta. Från 2001 var jag av olika anledningar (biotopförändringar m.m.) tvingad att ta bort vissa holkgrupper och antalet undersökta holkar minskade till 94. Avståndet mellan holkarna var mellan 15 och 30 meter och de satt i grupper med 10 eller 15 stycken. Avståndet mellan grupperna var 50-300 meter. Samtliga holkar var av traditionell "låd-typ" och helt öppningsbara (framsidan). Alla holkar satt på en höjd av endast 1,9-2,2 meter för att underlätta såväl studier som ringmärkning. Antal holkar av olika typer var åren 1986-2000 följande: 87 små holkar med håldiameter $35 \mathrm{~mm}, 32$ medelstora holkar med håldiameter $50 \mathrm{~mm}$ och 14 större holkar. Under perioden 2001-2005 var motsvarande antal 68,17 respektive 9 . Holkarna med håldiametern 35 $\mathrm{mm}$ var de som främst användes av flugsnapparna. De hade en bottenyta på $12 \times 12 \mathrm{~cm}$.

Holkarna besöktes med få undantag minst en gång per vecka från mitten av april till början av juli. Även senare häckningar följdes upp. Oftast blev det fler än ett besök i veckan, främst under perioden från färdigt bo till dess att första ägget lagts, då vissa holkar kontrollerades mer eller mindre dagligen. Totalt registrerades 24.362 olika häckdata (1218 per år) och den bedömda "arbetsinsatsen" var ca 1800 timmar (ca 90 tim/år).

När jag i den fortsatta redovisningen analyserar beståndsutvecklingen för de olika arterna tar jag endast med de 94 holkar som under samtliga 20 år suttit på samma plats. I övriga redovisningar (äggläggningsdatum, kullstorlek etc.) använder jag dock hela materialet. När jag redovisar antalet häckningar av olika arter är kriteriet för en häckning att minst ett ägg lagts. Det gäller även svartvit flugsnappare i de 94 holkar som använts för att analysera denna art. Uppgifterna om kullstorlek

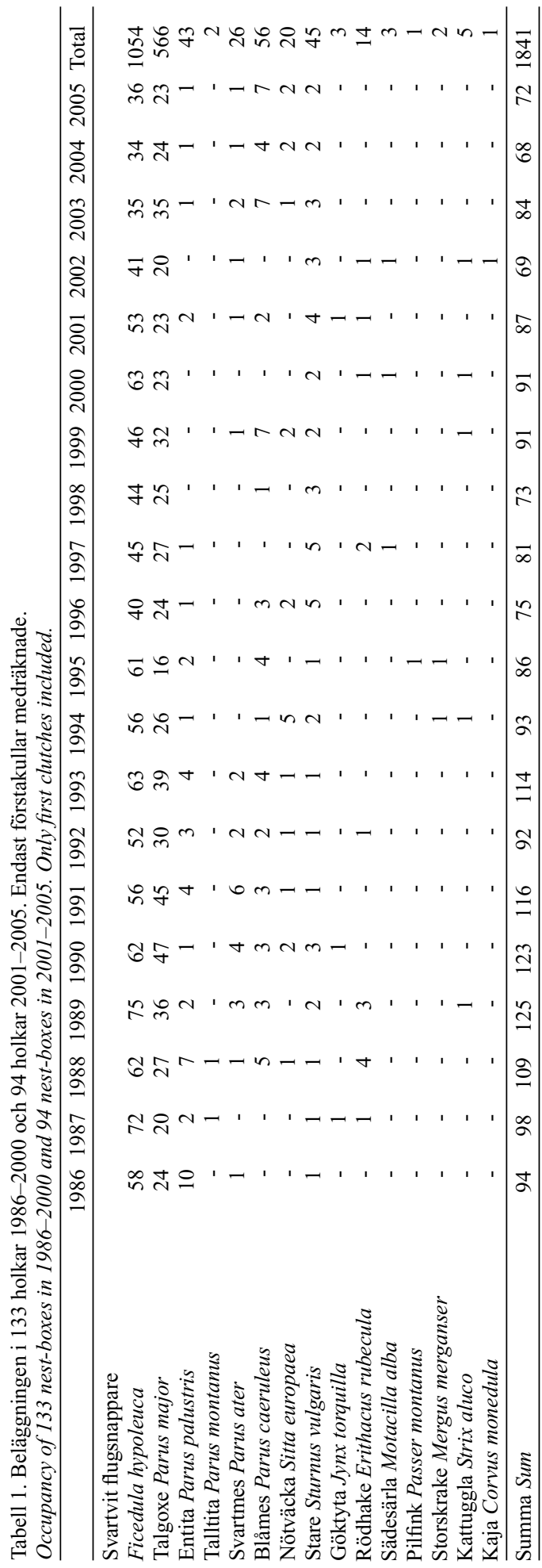


och häckningsresultat utgår däremot endast från fullagda kullar.

Datum för första äggets läggning kunde i många fall fastställas exakt. I övriga fall beräknades detta datum utifrån förutsättningen att ett ägg lades per dygn. Ett stort antal kontroller visade, att detta beräkningssätt är helt tillförlitligt. Vad gäller datum för den förste hanens ankomst bedömer jag säkerheten vara plus/minus en dag. Under den aktuella perioden gjordes dagliga turer i området för att så säkert som möjligt fastställa ankomstdatum.

\section{Resultat och diskussion}

\section{Det holkhäckande beståndet}

Tabell 1 visar hur de 1841 påbörjade häckningarna (minst ett ägg lagt) under perioden fördelade sig på olika arter. I likhet med andra studier är det två arter som helt dominerar - den svartvita flugsnapparen $(57 \%)$ och talgoxen (31\%). Tillsammans svarar de således för $88 \%$ av antalet häckningar. En motsvarande undersökning i Jämtland (Sjöberg 2006) visar ett liknande resultat (86\%). När det gäller talgoxe och svartmes tog jag endast med konstaterade förstakullar, inte omläggningar eller andrakullar. Det var i övrigt bara en art som häckade i mina holkar under samtliga 20 år - staren. Arten minskade dock drastiskt i området. Under 1960- och 1970-talen var situationen helt annorlunda, då det var mer eller mindre slagsmål om de lämpliga holkarna. En anledning till denna minskning anges ibland vara

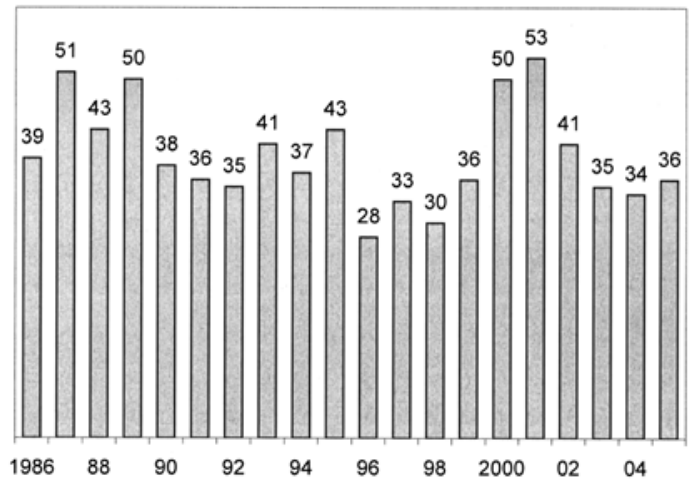

Figur 1. Antal påbörjade häckningar av svartvit flugsnappare i 94 holkar uppsatta på samma platser genom de 20 åren 1986-2005. Medelvärdet för alla säsonger var 39,5 häckningar.

Number of Pied Flycatcher clutches started in 94 nest-boxes that were present in identical positions throughout the 20 seasons 1986-2005. Mean of all seasons was 39.5 breeding attempts. den minskade arealen av betesmarker med djur. Detta äger dock ingen giltighet i mitt område, där djurhållningen varit tämligen konstant, trots att mjölkkorna bytts ut mot köttdjur och hästar.

Svartmesen och rödhaken uppvisade temporära uppgångar, men saknades också många år. I övrigt var det som synes fråga om ströhäckningar. Beläggningen i holkarna var i genomsnitt $75 \%$ när det gäller förstahäckningar. De tomma holkarna användes för omläggningar och andrakullar av främst talgoxe.

\section{Beståndsutveckling}

Antalet par av svartvita flugsnappare som startade häckningar (minst ett ägg lagt) framgår av Figur 1. I materialet ingår endast de 94 holkar som suttit på samma plats under hela perioden. Av de 789 häckningar som påbörjades (genomsnitt 39,5 holkar/år) var det endast 21 som inte ledde till fullagd kull $(2,7 \%)$. I elva av fallen kunde ingen orsak konstateras, häckningen avbröts utan känd anledning. I en holk påträffades honan död utan synliga skador och i de återstående fallen blev flugsnapparna bortkörda av andra djur, i fem fall av hasselmus, två av göktyta och lika många av talgoxe.

Beståndet i det aktuella området var långsiktigt stabilt. En svag tendens till växling mellan tre till fyra "goda år" och lika många efterföljande "dåliga år" kan skönjas i tabellen. Till de goda åren räknas 1987-1989 och 2000-2002 och en mindre uppgång kan också ses 1993-1995. Mellanliggande år visade beståndet siffror under genomsnittet. Tidsperioden är alltför kort för att man skall kunna bedöma om det bara är fråga om tillfälligheter eller om det finns en mer långsiktig tendens $\mathrm{i}$ den antydda cykliska dynamiken. Om det senare skulle vara fallet bör det åter ske en uppgång under åren 2006-2008 (2006 blev det 40 häckningar dvs. en mindre uppgång, likaså 2007 med 44 häckningar).

Hur det svenska beståndet av svartvit flugsnappare utvecklats generellt sedan 1986 förefaller oklart. Enligt Svensk Fågeltaxering (Lindström \& Svensson 2007) minskade beståndet under perioden 1986-1984, men har därefter hållit sig oförändrat eller ökat. Fågelstationernas standardiserade fångster visade varken vår eller höst några signifikanta trender åren 1986-2005 (Lindström m.fl. 2007, Falsterbo fågelstations hemsida). Det tycks finnas stora regionala skillnader. I Figur 2 visas en jämförelse mellan mitt material och den tidigare nämnda studien i Jämtland. Intressant är att notera att båda undersökningarna under åren 1986-1996 (11 år) är mycket samstämmiga i beståndsvaria- 


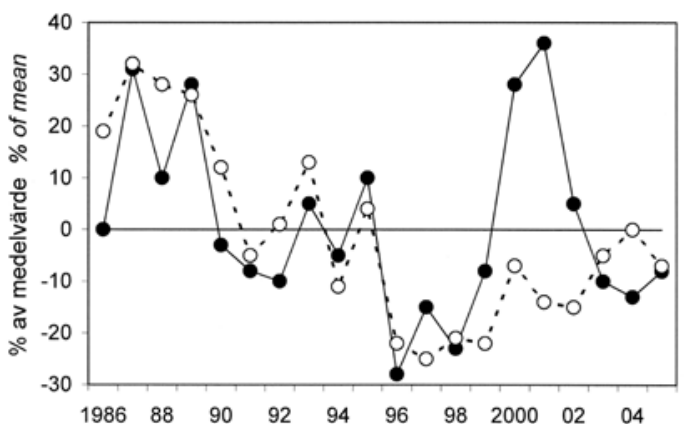

Figur 2. Jämförelse mellan beståndsutvecklingen för svartvit flugsnappare i denna undersökning (•) och en i Jämtland (o) (Sjöberg 2006). Talen ges som procent av medelvärdena. Flycatcher population fluctuations, expressed as deviations from the means for all seasons, in this study (•) and a study in the province of Jämtland, northern Sweden (०) (Sjöberg 2006).

tionen $(\mathrm{r}=0,87, \mathrm{p}<0,001)$. Räknat på hela undersökningsperioden blir motsvarande siffror: $r=0,52$, $p<0,02$. Samma fenomen framträder vid jämförelse med en långtidsstudie i Närke (Schölin 2007), dvs. en samvariation fram t.o.m. just år 1996, varefter utvecklingen även här skiljer sig från mina resultat. Noterbart är också, att den markanta uppgången av beståndet i mitt område 2000-2002 inte hade någon motsvarighet vare sig i Jämtland eller i Närke. Huruvida orsakerna till dessa regionala skillnader i beståndsutvecklingen står att finna inom de aktuella områdena eller i artens vinterkvarter är oklart.

\section{Ankomst och äggläggning}

I Figur 3 presenterar jag datum dels för de första hanarnas ankomst till området, dels för värpstarten. I den tidigare nämnda studien i Jämtland fanns ett tydligt samband mellan dessa två variabler, medan det $\mathrm{i}$ mitt material inte finns någon samvariation $(\mathrm{r}=0,34 ; \mathrm{p}>0,10)$. Inte heller fanns det någon trend i vare sig hanarnas ankomst $(-0,25$ dagar per år; $\mathrm{r}=0,38 ; \mathrm{p}>0,05)$ eller värpstart $(-0,14$ dagar per år; $r=0,19 ; p>0,10)$. En långtidsstudie i mellersta Värmland (Borgström \& Schütt 2006) visar att arten numera anländer nio dagar tidigare än vid undersökningens start 1938.

När den första hanen anlänt brukade det dröja ca en vecka innan den första honan observerades. Några detaljstudier över i vilken takt beståndet sedan fylls på i området gjordes inte men förloppet tycktes variera kraftigt mellan åren. Datum för de olika kullarnas värpstart skulle möjligen kunna ge en indikation på $\mathrm{i}$ vilken takt honorna anlände till området. I Tabell 2 redovisas därför värpstarten $\mathrm{i}$ femdagarsperioder. Här framträder stora skillnader mellan åren. Vissa år är värptiden mycket koncentrerad (t.ex. 1986, 1995), andra tydligt förlängd (t.ex. 1987, 1992, 1999) medan det ibland kan skönjas flera toppar (t.ex. 2005). Vad som orsakar denna spridning av häckstarten (fåglarnas ankomst) blir endast spekulationer, men torde ha sin förklaring i bl.a. väderläget och därmed sammanhängande betingelser under den senare delen av flyttningen genom norra Europa.

När det gäller de sena kullarna (sista halvan av juni) kan orsakerna givetvis vara flera. Kanske handlar det helt enkelt om sent anlända honor och/ eller omläggningar. En annan orsak skulle kunna vara att det vissa år fanns ett överskott på honor och att dessa fick invänta en sent anländande hane, eller en, som redan hade en ruvande hona i en annan holk. Det är väl känt att flugsnapparhanen har polygama böjelser. Det ska noteras, att jag aldrig kunde konstatera någon omläggning eller andrakull hos arten, trots att de flesta honor ringmärktes under början av ruvningsperioden. Någon ringmärkt hona hittades aldrig vid kontroll av de sena kullarna. Detta tyder på att omläggningar hos svartvit flugsnappare, om de alls förekommer, är begränsade till äggläggningsperioden.

Bobyggnaden tog i allmänhet ca 4-7 dagar (75\%), ibland endast tre dagar (9\%), men det kunde också ta längre tid 8-11 dagar (16\%). Genomsnittstiden för de 88 fall jag kunde följa var ca sex dagar. När

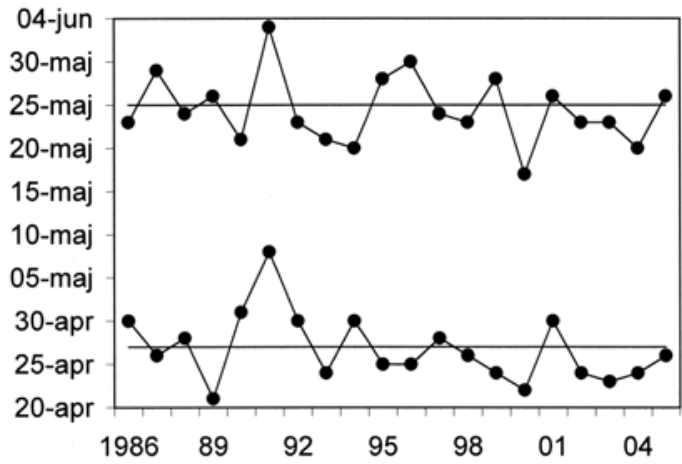

Figur 3. Medeldatum för värpstart varje år (över kurvan; medelvärde alla år 25 maj) och datum för första hanens ankomst (nedre kurvan; medelvärde 27 april) hos svartvit flusnappare.

Mean yearly laying dates (upper graph; mean all years 25 May) and first arrival date of males (lower graph; mean 27 April) of Pied Flycatchers in study area. 

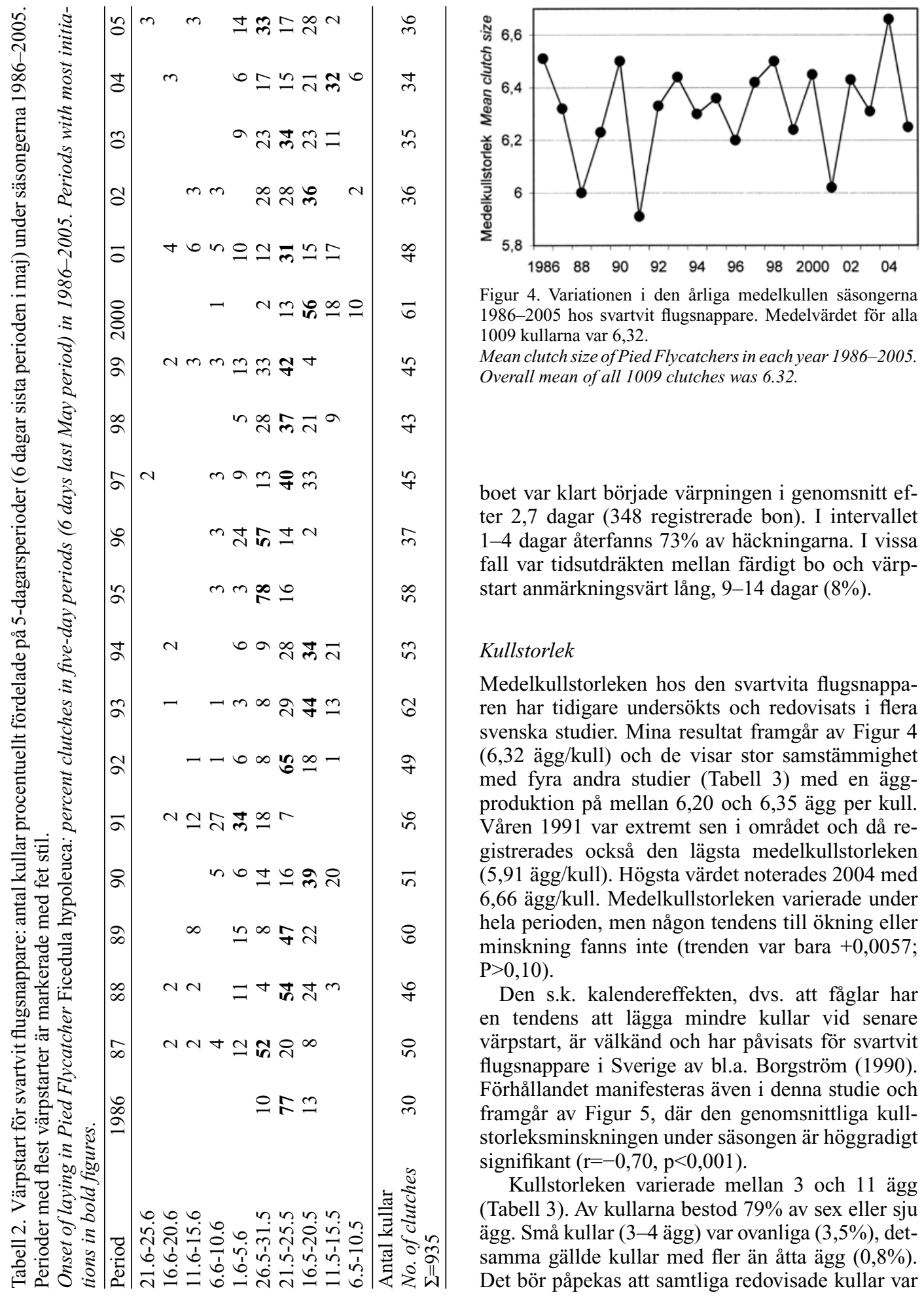

Figur 4. Variationen i den årliga medelkullen säsongerna 1986-2005 hos svartvit flugsnappare. Medelvärdet för alla 1009 kullarna var 6,32.

Mean clutch size of Pied Flycatchers in each year 1986-2005. Overall mean of all 1009 clutches was 6.32 .

boet var klart började värpningen i genomsnitt efter 2,7 dagar (348 registrerade bon). I intervallet 1-4 dagar återfanns $73 \%$ av häckningarna. I vissa fall var tidsutdräkten mellan färdigt bo och värpstart anmärkningsvärt lång, 9-14 dagar (8\%).

\section{Kullstorlek}

Medelkullstorleken hos den svartvita flugsnapparen har tidigare undersökts och redovisats i flera svenska studier. Mina resultat framgår av Figur 4 (6,32 ägg/kull) och de visar stor samstämmighet med fyra andra studier (Tabell 3) med en äggproduktion på mellan 6,20 och 6,35 ägg per kull. Våren 1991 var extremt sen i området och då registrerades också den lägsta medelkullstorleken (5,91 ägg/kull). Högsta värdet noterades 2004 med 6,66 ägg/kull. Medelkullstorleken varierade under hela perioden, men någon tendens till ökning eller minskning fanns inte (trenden var bara $+0,0057$; $\mathrm{P}>0,10$ ).

Den s.k. kalendereffekten, dvs. att fåglar har en tendens att lägga mindre kullar vid senare värpstart, är välkänd och har påvisats för svartvit flugsnappare i Sverige av bl.a. Borgström (1990). Förhållandet manifesteras även i denna studie och framgår av Figur 5, där den genomsnittliga kullstorleksminskningen under säsongen är höggradigt signifikant $(r=-0,70, p<0,001)$.

Kullstorleken varierade mellan 3 och 11 ägg (Tabell 3). Av kullarna bestod $79 \%$ av sex eller sju ägg. Små kullar (3-4 ägg) var ovanliga (3,5\%), detsamma gällde kullar med fler än åtta ägg $(0,8 \%)$. Det bör påpekas att samtliga redovisade kullar var 
fullagda, d.v.s. ruvningen hade igångsatts. När det gäller de sju kullarna med 9-11 ägg (4 kullar med 9 ägg, en kull med 10 ägg och 3 kullar med 11 ägg) är det inte osannolikt att flera honor var inblandade, men några observationer av att så var fallet finns inte, varför jag valt att ta med dessa i redovisningen. I ett fall har jag kunnat konstatera att två honor samhäckat i holken (Nilsson 2005) och denna kull har utelämnats.

För att undersöka om det finns några geografiska skillnader i kullstorleken jämför jag i Tabell 3 mina resultat med fyra andra större material. Medelkullstorleken visar, som tidigare nämnts, god samstämmighet. Detsamma gäller de två studierna från Tranås-trakten (Jansson 1960, denna studie) vad beträffar fördelningen mellan olika kullstorlekar, trots att 40 år förflutit mellan undersökningarna. Vid jämförelse med de övriga tre undersökningarna i mellersta Sverige framgår dock två avvikelser - dels att dominansen av 6-kullar var större i mellansverige (58,6\% mot $41,1 \%$ i mitt material), dels att andelen små kullar (3-4 ägg) var lägre. Om de småländska och mellansvenska resultaten jämförs med hjälp av ett $\chi^{2}$-test visar det sig, att de båda fördelningsmönstren skiljer sig höggradigt signifikant $\left(\chi_{224}^{2}=65,8, p<0,001\right)$.

\section{Häckningsutfall}

Samtliga häckningar följdes till dess ungarna lämnat holken. Arten utsätts vissa år för omfat-

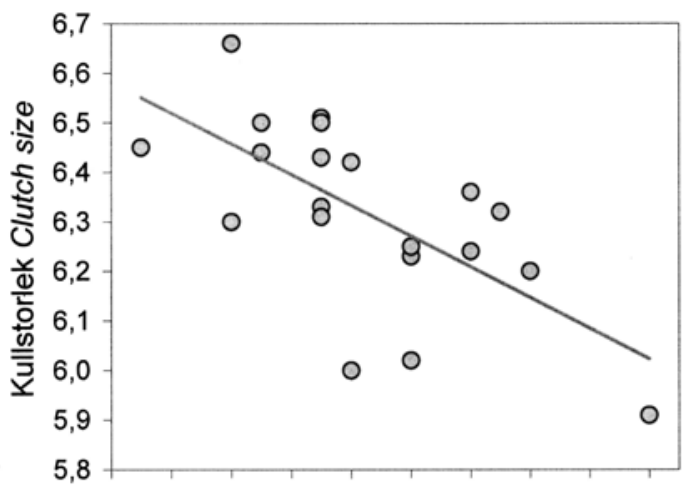

16- 18- 20- 22- 24- 26- 28- 30- 01- 03maj maj maj maj maj maj maj maj jun jun

Värpstart Start of egg-laying

Figur 5. Sambandet mellan de årliga medelvärdena för värpstart och kullstorlek hos svartvit flugsnappare åren 1986-2005.

The relationship between mean clutch size and mean laying date for Pied Flycatchers in 1986-2005. 
Tabell 4. Häckningsresultat för svartvit flugsnappare i säsongerna 1986-2005.

Breeding performance of the Pied Flycatcher in 1986-2005.

\begin{tabular}{ccccccc}
\hline $\begin{array}{c}\text { År } \\
\text { Year }\end{array}$ & $\begin{array}{c}\text { Antal } \\
\text { kullar } \\
\text { Number of } \\
\text { clutches }\end{array}$ & $\begin{array}{c}\text { Antal } \\
\text { ägg } \\
\text { Number of } \\
\text { eggs }\end{array}$ & $\begin{array}{c}\text { Antal } \\
\text { kläckta } \\
\text { Number } \\
\text { hatched }\end{array}$ & $\begin{array}{c}\text { Antal } \\
\text { flygga } \\
\text { Number } \\
\text { fledged }\end{array}$ & $\begin{array}{c}\text { Antal flygga } \\
\text { per kull } \\
\text { Number fledged } \\
\text { per brood }\end{array}$ & $\begin{array}{c}\text { Procent flygga } \\
\text { av lagda ägg } \\
\text { Percentage } \\
\text { fledged }\end{array}$ \\
\hline 1986 & 53 & 345 & 264 & 230 & 4.34 & 67 \\
1987 & 66 & 417 & 330 & 306 & 4.64 & 73 \\
1988 & 58 & 348 & 295 & 283 & 4.88 & 81 \\
1989 & 66 & 411 & 276 & 206 & 3.12 & 50 \\
1990 & 60 & 390 & 351 & 299 & 4.98 & 77 \\
1991 & 55 & 325 & 272 & 262 & 4.76 & 81 \\
1992 & 52 & 329 & 307 & 263 & 5.06 & 80 \\
1993 & 61 & 393 & 338 & 252 & 4.13 & 64 \\
1994 & 56 & 353 & 317 & 270 & 4.82 & 77 \\
1995 & 61 & 388 & 339 & 229 & 3.75 & 59 \\
1996 & 40 & 248 & 202 & 157 & 3.93 & 63 \\
1997 & 45 & 289 & 270 & 189 & 4.20 & 65 \\
1998 & 44 & 286 & 243 & 185 & 4.21 & 65 \\
1999 & 42 & 262 & 208 & 156 & 3.71 & 60 \\
2000 & 62 & 400 & 337 & 285 & 4.60 & 71 \\
2001 & 48 & 289 & 216 & 134 & 2.79 & 46 \\
2002 & 40 & 257 & 237 & 201 & 5.03 & 78 \\
2003 & 32 & 202 & 176 & 140 & 4.38 & 69 \\
2004 & 32 & 213 & 165 & 138 & 4.31 & 65 \\
2005 & 36 & 225 & 175 & 127 & 3.53 & 56 \\
\hline Total & 1009 & 6370 & 5318 & 4312 & & 68 \\
Medel & & & & & 4,27 & \\
\hline
\end{tabular}

tande predation och andra häckförluster. Av Tabell 4 framgår utfallet för samtliga år. Variationerna mellan åren är som synes stora. 1989 och 2001 får betecknas som rena "katastrofår" för arten, då ungproduktionen endast blev ca tre ungar per kull. Noterbart är, att de påföljande åren blev goda.

Medeltalet producerade ungar per kull, 4,27, ligger långt under vad man funnit $\mathrm{i}$ de andra svenska studier, som jag jämfört mina resultat med. Samtliga dessa studier redovisar siffror på mellan 5,27 och 5,57 ungar per kull, d.v.s. drygt 25\% högre än i min undersökning. Orsaken står säkert att finna i att våra undersökningar skett i skilda miljöer, mellan vilka predationstrycket sannolikt varierar, så även lokala väderfaktorer. Kanske är antalet mindre i andra områden än i de ovannämnda svenska. Att häckningsutfallet är dåligt i mitt område framgår klart vid jämförelse med de angivna studierna. Några exempel:

- endast $84 \%$ av äggen kläcktes (i övriga studier 92-97\%)

- $81 \%$ av kläckta ägg resulterade i flygga ungar (91-96\%)
- $68 \%$ av de lagda äggen blev flygga ungar $(86-91 \%)$.

\section{Häckningsförluster, störningar}

Den svartvita flugsnapparen utsattes således för stora förluster av ägg och ungar under häckperioden. I Tabell 5 görs ett försök att närmare analysera deras omfattning och i vilket skede av häckprocessen de inträffade. Andelen helt lyckade häckningar, dvs. där samtliga ägg resulterade i flygga ungar, utgjorde endast ca $40 \%$ under hela undersökningsperioden, en andel som visade en fortlöpande svag men signifikant minskning under de 20 säsongerna $(\mathrm{r}=-0,50, \mathrm{p}<0,05)$. Om denna andel i stället definieras som kullar där minst en unge blivit flygg, ökar den till 80\%. Även denna siffra är klart lägre än de som redovisas i de övriga svenska studierna. I $35 \%$ av häckningarna uppstod häckningsförluster i form av ägg som inte kläcktes. Totalantalet ägg som inte kläcktes var 487 , dvs. ca $8 \%$ av samtliga lagda ägg. I de flesta fallen rörde det sig om 1-2 okläckta ägg/kull, men upp till fem ägg noterades. 


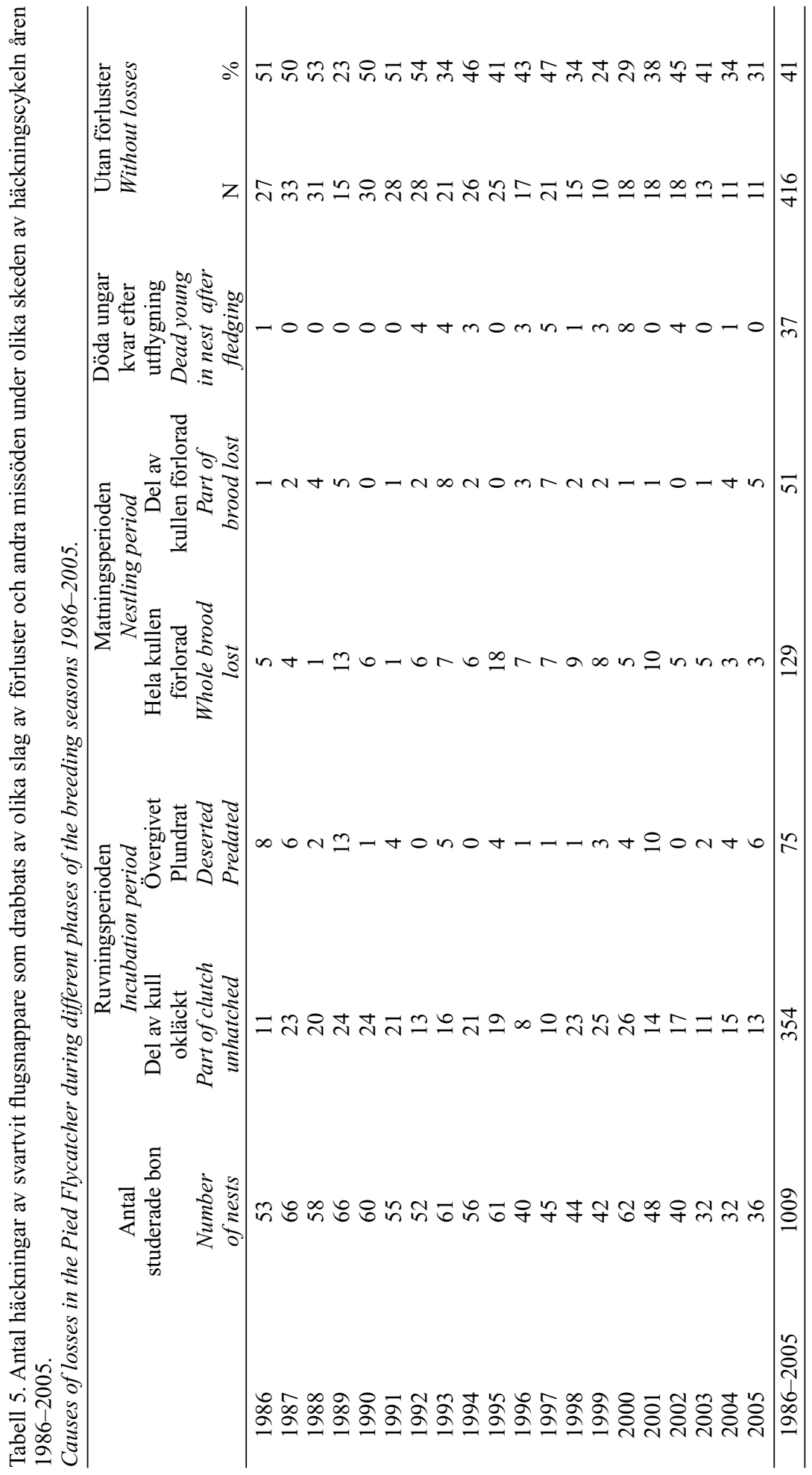


Ibland ratades också lagda ägg av honan som föste upp dem på bokanten. Fenomenet har tidigare behandlats och diskuterats av Nilsson (2005) och grundligt studerats av Lobato et al. (2006). Företeelsen förekom mycket sparsamt i min studie, eftersom endast 24 bon med ägg på bokanten registrerades, de flesta (14 st) under perioden 1990-1994. En jämförelse med den ovannämnda spanska studien antyder att frekvensen av bon med uppfösta ägg är av samma storleksordning på båda hållen; i medeltal 2,8 repektive 2,4 fall per 100 häckningar i det spanska resp. småländska häckområdena (det spanska värdet framräknat på basis av uppgifter i Moreno et al. (2005) och Lobato et al. (2006)). Ägguppfösningen skedde i mina holkar under såväl värpperioden (6 fall) som ruvningstidens första och andra vecka (7 resp. 11 fall). Vad gäller konstaterade uppfösta ägg under äggläggningstiden kan det inte uteslutas, att de i något eller några fall värptes direkt på bokanten.

De häckningar som spolierades under ruvningstiden utgjorde ca 7\% (75 st) av det totala antalet fullagda kullar. I de flesta fall handlade det om att bona av okänd anledning övergavs (30 fall) eller att de rövades av predatorer (29 fall). I fem fall hittades honan död i holken. I övriga fall kördes flugsnapparna bort av talgoxar och hasselmöss. De största förlusterna (129 fall, 13\%) noterades under uppfödningsskedet. Predation av mård kunde konstateras i 40 fall. I 62 fall kunde jag endast konstatera att boet rövats av "okänt djur". Jag skulle tro att mården låg bakom även många av dessa noteringar. Regn och kyla ledde i vissa fall till att ungarna övergavs och i några fall övertogs boet av hasselmöss även under matningsskedet.

Vissa kullar blev inte helt spolierade utan en eller flera ungar kom på vingarna (51 kullar, 5\%). I en del fall handlade det om dåligt väder med regn och kyla, vilket medförde att föräldrarna hade svårt att hitta föda åt ungarna. Mårdens speciella jaktsätt resulterade också $i$ att någon eller några ungar överlevde angreppet. Boet drogs ut genom ingångshålet, vilket resulterade $i$ att några ungar ibland trillade ner på holkens golv. Om jag i tid lyckades ta bort boresterna i hålet, fortsatte föräldrarna att mata de kvarvarande ungarna. Vid min slutkontroll av holkarna hände det i 37 fall (4\%) att jag hittade en eller flera döda ungar i balen, troligen p.g.a. födobrist i slutet av matningsskedet. Minst en unge (oftast flera) hade dock lämnat boet i dessa fall.

Mycket tyder på att mitt holkområde var utsatt för ett osedvanligt hårt predationstryck. Förutom mårdar och hasselmöss kunde även ekorrar och småvesslor misstänkas ligga bakom det dåliga häckningsutfallet, så även den under vissa år frekventa etableringen av geting- och humlebon i holkarna.

\section{Ringmärkning, kontroller}

Min strävan var att ringmärka så många som möjligt av de ruvande honorna. Tyvärr var jag av olika skäl tvungen att göra ett uppehåll i märkningarna under åren 1996-1999, men kontroller av tidigare märkta honor fortsatte dock som tidigare. Under de återstående 16 åren producerades 838 kullar och 4395 ungar kläcktes. Jag lyckades ringmärka eller kontrollera 638 av de ruvande honorna $(76 \%)$ och 3653 av ungarna (83\%).

Det är välkänt att återfyndsprocenten är mycket låg för våra småfåglar och mina resultat utgör inget undantag. Endast elva fåglar märkta som boungar har kontrollerats $(0,3 \%)$, sju inom mitt holkområde och fyra inom "regionen" (Tranås, Aneby, Jönköping och Mullsjö kommuner). Mina egna kontroller av ringmärkta honor visar ett klart bättre resultat 88 återkomster (16\%). Av dessa återfanns 28 inom samma holkserie ( $\max 200$ meter från märkplatsen) och sju i samma holk som de märktes. Utöver detta har sex kontroller gjorts, där ringmärkningen utförts av andra (i Aneby och Jönköpings kommuner, endast några mil från mitt område), fyra av dessa var ringmärkta som boungar.

Slutsatsen av dessa noteringar synes tämligen klar - ungar återvänder sällan till sin födelseplats. Äldre honor tycks däremot ha en uttalad strävan att återvända till sitt tidigare häckningsområde. De skulle kunna betecknas som "partiellt ortstrogna". Detta är iakttagelser, som konstaterades redan på 1940-talet (Enemar 1948, von Haartman 1949) och som också framgår av en holkstudie i mina hemtrakter (Jansson 1960). Dessa tre undersökningar anger att mellan $10-15 \%$ av märkta $2 \mathrm{~K}+$ honor återvänder till sina hemmamarker, vilket väl stämmer överens med mina noteringar. Här synes förhållandena vara stabila, trots att 60 år förflutit. Noterbart är också, att av de 5114 svartvita flugsnappare jag totalt märkt i området under årens lopp, har varken återfynd eller kontroller rapporterats utanför min egen region (nordligaste Jönköpings län).

I Tabell 6 redovisas samtliga 88 kontroller som gjorts av ringmärkta honor under perioden (t.o.m. 2007). Ytterligare två noteringar finns i materialet - två honor märkta före 1986 (en 6K+ och en $7 \mathrm{~K}+$ ). Som förväntat påträffades de flesta honorna året efter ringmärkningen $(3 \mathrm{~K}+)$ och de äldsta fåglar som noterats blev minst sju år gamla. I flera fall påträffades samma hona $\mathrm{i}$ holkområdet såväl två som 
Tabell 6. Antal ringmärkta och antal återfångade honor av svartvit flugsnappare fördelade på antal år efter ringmärkningen vid minst ett års ålder $(=2 \mathrm{~K}+)$.

Number of female Pied Flycatchers ringed (i.e. when at least one year old, $2 K^{+}$) that were recaptured in subsequent years (i.e. at ages $3 K+, 4 K+$, etc.).

\begin{tabular}{lccccccc}
\hline \multirow{2}{*}{$\begin{array}{l}\text { Year } \\
\text { Year }\end{array}$} & $\begin{array}{c}\text { Antal ringmärkta } \\
\text { Number ringed }\end{array}$ & \multicolumn{5}{c}{$\begin{array}{c}\text { Antal återfångster vid en ålder av } \\
\text { Number retrapped at the age of }\end{array}$} \\
\cline { 3 - 7 } & & $3 \mathrm{~K}+$ & $4 \mathrm{~K}+$ & $5 \mathrm{~K}+$ & $6 \mathrm{~K}+$ & $7 \mathrm{~K}+$ & $3 \mathrm{~K}+-7 \mathrm{~K}+$ \\
\hline 1986 & 19 & 4 & 0 & 0 & 0 & 0 & 4 \\
1987 & 36 & 1 & 2 & 1 & 0 & 0 & 4 \\
1988 & 19 & 2 & 1 & 1 & 1 & 1 & 6 \\
1989 & 38 & 5 & 1 & 1 & 0 & 0 & 7 \\
1990 & 35 & 1 & 0 & 1 & 0 & 0 & 2 \\
1991 & 45 & 4 & 1 & 0 & 0 & 0 & 5 \\
1992 & 37 & 4 & 4 & 1 & 0 & 0 & 9 \\
1993 & 46 & 1 & 1 & 1 & 0 & 0 & 3 \\
1994 & 44 & 4 & 1 & 1 & 0 & 0 & 6 \\
1995 & 33 & 2 & 4 & 1 & 0 & 0 & 7 \\
$1996-1999$ & 0 & - & - & - & - & - & - \\
2000 & 60 & 8 & 4 & 1 & 0 & 0 & 13 \\
2001 & 32 & 3 & 1 & 1 & 1 & 0 & 6 \\
2002 & 29 & 3 & 1 & 1 & 0 & 0 & 5 \\
2003 & 20 & 1 & 0 & 0 & 0 & 0 & 1 \\
2004 & 30 & 6 & 1 & 0 & 0 & 0 & 7 \\
2005 & 27 & 3 & 0 & 0 & 0 & 0 & 3 \\
\hline Alla All & 550 & 52 & 22 & 11 & 2 & 1 & 88 \\
\hline
\end{tabular}

Tabell 7. De olika åldersklassernas återkomstfrekvens totalt hos svartvit flugsnappare i tre fennoskandiska undersökningar.

Overall return rate of female Pied Flycatchers of different age categories in three Fennoscandian studies.

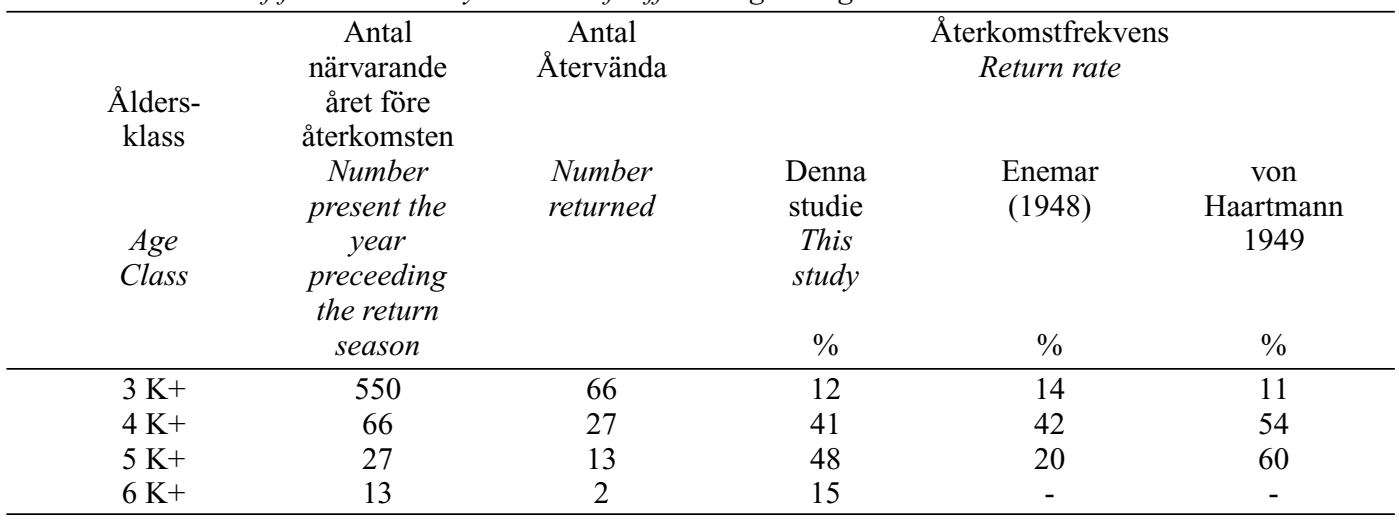

tre år i rad efter märkningen. Som framgår ovan lyckades jag inte kontrollera samtliga honor och det fanns dessutom fler lämpliga boplatser inom mitt område. Det finns dock anledning att tro, att de "gluggar" som finns i de individuella kontrollerna innebär, att honan sannolikt fanns i området, men ej kunde kontrolleras. Av Tabell 7 framgår de olika åldersklassernas återkomstfrekvens och jämförel- ser med resultaten från 1940-talet, vilka redovisats enligt samma beräkningsmodell, dvs. att även "gluggarna" har medtagits. Samtliga värden skall ses som minimivärden. Av tabellen framgår en viss variation mellan olika områden, men också, att det finns en manifesterad strävan hos flugsnapparhonorna att de närmast följande åren återvända till sin första häckplats. Detta gäller främst det andra och 
tredje året efter märkning, då procenttalen överensstämmer väl med den hittills kända överlevnadsprocenten hos arten (40-50\%). Mitt relativt stora återfyndsmaterial stöder von Haartmans tolkning, att de honor som återvänt till häckplatsen en gång fortsätter att återvända ortstroget livet ut. När det gäller fåglar som återvänder ännu senare (som $6 \mathrm{~K}+$ eller äldre) är materialet alltför litet för att tillåta några mer långtgående slutsatser, men har medtagits för att visa att enstaka honor kan bli relativt gamla.

\section{Tack}

Som tidigare nämnts hade denna publicering inte kommit till stånd utan Anders Enemars inspirerande, oegennyttiga och föredömligt pedagogiska hjälp med att omsätta mina fältdagböckers innehåll till strukturerade resultat och slutsatser inom den för mig hittills okända vetenskapliga världen. Ett stort tack till en av våra förgrundsfigurer inom svensk ornitologi, jag känner mig verkligen både hedrad och utvald! Ett tack också till datachefen i Tranås kommun, Kjell Pettersson, som hjälpt mig med att utifrån en mängd siffror och data utforma de tabeller och figurer som ingår i uppsatsen.

\section{Referenser}

Borgström, E. 1990. Häckningsdata om svartvit flugsnappare Ficedula hypoleuca i mellersta Sverige. Vår Fågelvärld 49: 140-146.

Borgström, E. \& Schütt, L. 2006. En långtidsstudie (1938-2004) om flyttfåglarnas ankomst till mellersta Värmland. Ornis Svecica 16: 95-111.

Enemar, A. 1948. Några erfarenheter från fem års holkfågelstudier. Vår Fågelvärld 7: 105-117.

Enemar, A. 1998. Ornis Svecica - en mötesplats för fågelbiologer. Ornis Svecica 9: 97-98.

Haartman, L.von 1949. Svartvita flugsnapparens, Muscicapa hypoleuca (Pall.), hemortstrohet. Vår Fågelvärld 8: 74-80.

Jansson, K-E. 1960. Några siffror och rön från sju års studier av småfåglar häckande i holkar. Vår Fågelvärld 19: $127-136$.

Johansson, H. 1972. Clutch size and breeding success in some hole-nesting passerines in Central Sweden. Ornis Fennica 49: 1-6.

Lindström, Å., Andersson, A., Eriksson, A. \& Waldenström, J. 2007. Fågelräkning och ringmärkning vid Ottenby 2006. Ottenby fågelstation, Sveriges Ornitologiska Förening.

Lindström, Å. \& Svensson, S. 2007. Övervakning av fäglarnas populationsdynamik. Arsrapport för 2006. Ekologiska Institutionen, Lunds Universitet, $68 \mathrm{pp}$.

Lobato, E., Moreno, J., Merino, S., Sanz, J.J., Arriero, E., Tomás, G. \& Martinez-de la Puente, J. 2006. Maternal clutch reduction in the pied flycatcher Ficedula hypoleu$c a$ : an undescribed clutch size adjustment mechanism. $J$.
Avian Biol. 37: 637-641.

Lundberg, A. \& Alatalo, R.V. 1992. The Pied Flycatcher. Poyser, London.

Moreno, J., Merino, S., Sanz, J.J., Morales, J. \& Tomás, G. 2005. Nestling cell-mediated immune respons, body mass and hatching date as predictors of local recruitment in the pied flycatcher Ficedula hypoleuca. J. Avian Biol. 36: 251-260.

Nilsson, J.E. 2005. Reduktion av antalet ägg i kullen hos två samhäckande svartvita flugsnapparhonor Ficedula hypoleuca. Ornis Svecica 15: 44-46.

Schölin, K G. 2007. Häckningsresultat för svartvit flugsnappare Ficedula hypoleuca 1948-2004. Fåglar i Närke 30: 12-16.

Sjöberg, N. 2006. Ankomstdatum 1948-2006 och häckning 1978-2006 i Jämtland för svartvit flugsnappare Ficedula hypoleuca, rödstjärt Phoenicurus phoenicurus och lövsångare Phylloscopus trochilus. Ornis Svecica 16: 112-117.

\section{Summary}

\section{Introduction}

The study area is situated in the parish of Linderås $\left(57^{\circ} 58^{\prime} \mathrm{N}, 14^{\circ} 15^{\prime} \mathrm{E}\right)$ between the towns of Tranås and Gränna in south-eastern Sweden. Nest-boxes of various sizes had been present since 1957, but a systematic monitoring of the breeding population did not start until 1986, the first year of the 20 breeding seasons presented here. My aim was to follow as closely as possible the breeding events in the boxes, mainly for fun but also to contribute to a nation-wide nest-box project organised at the Department of Animal Ecology, Lund University. This means that a large amount of data has been accumulated, mainly on some small passerine species. I have chosen to present an overview of the total nest-box breeding population throughout the 20 years and then select the breeding biology of the Pied Flycatcher (scientific names of species in Table 1) to be accounted for in detail. Although this species has since long been thoroughly investigated (e.g., Lundberg \& Alatalo 1992), I will restrict my comparisons to the results of some few long-term nest-box studies in the southern half of Sweden.

\section{Study area and methods}

The study area is characterized by farmland and deciduous woods with only minor patches of coniferous forest, more or less impenetrable shrubbery and swampy zones. Dominating trees are alder $\mathrm{Al}$ nus glutinosa, aspen Populus tremula, bird cherry Prunus avium and birch Betula spp. Pastures with grazing cattle cover large areas.

The number of nest-boxes was 133 from 1986 
to 2000 , but was then reduced to 94 . They were erected 15 to $30 \mathrm{~m}$ apart at 1.9 to $2.2 \mathrm{~m}$ above the ground in groups, each consisting of 10 to 15 boxes and located 50 to $300 \mathrm{~m}$ apart. Most nest-boxes (about 70\%) were small with $35 \mathrm{~mm}$ entrance hole and a bottom area of $12 \times 12 \mathrm{~cm}$, suitable for small passerines, including the Pied Flycatchers. About $20 \%$ were of medium size with $50 \mathrm{~mm}$ entrance and the remaining ten percent were larger.

The nest-boxes were inspected at least once a week from about mid-April to mid-July. For the analysis of population fluctuations, only those 94 nest-boxes were considered that remained in the same position throughout the 20 seasons. Otherwise the breeding data from all occupied boxes were used.

\section{The total nest-box breeding community (Table 1)}

Nests in which at least one egg was laid were accepted as indicating a breeding pair. On average, $75 \%$ of the nest-boxes were occupied by first broods (replacement and second clutches were disregarded). No less than 15 species were recorded, let alone half of them only occasionally. The Pied Flycatcher and the Great Tit always dominated as in other nest-box studies in Sweden, even further to the north (Sjöberg 2006). Apart from these two species, only the Starling bred in my boxes all 20 seasons. This species has decreased in number dramatically since the 1970 s when practically all suitable nest-boxes were occupied annually. Henceforth only the breeding data and behaviour of the Pied Flycatcher are considered in this paper.

\section{Population dynamics}

Figure 1 shows the fluctuations in number of initiated breeding attempts throughout the 20 seasons. Of the 789 clutches started 21 (2.7\%) were never completed. The flycatcher population remained fairly stable. The observable weak decline is far from statistically significant. Three to four good years alternated with an equal number of poor years in a seemingly regular manner, indicating a periodicity that is further strengthened by the increase in population numbers after the study was ended in 2005 (40 and 44 pairs in 2006 and 2007, respectively).

The fluctuation pattern is in surprisingly good accordance with that of two long-term investigations elsewhere in Sweden. Figure 2 compares the fluctuations in my study area with those in Sjöberg's (2006) nest-box area located about 650 $\mathrm{km}$ northwards. The direction of the changes are in good agreement during the first ten years $(\mathrm{r}=0.87$, $\mathrm{p}<0.01$ ) but differ more thereafter (correlation for all 20 years, $r=0.52, p<0.02$ ). A comparison with a flycatcher population about $150 \mathrm{~km}$ NNE of Linderås (Schölin 2007) shows mainly the same pattern of agreement. However, these two studies do not show the steep rise in the breeding population that occurred in my study area from 2000 to 2002.

\section{Time of arrival and egg laying}

The arrival date of the first male in spring and the date of the first egg varied between years (Figure 3) with mean dates of 27 April and 25 May, respectively. The two parameters fluctuate independently and show no significant trend over the 20 years. The first observed females appeared about one week later than the males. The seasons differed as to the time course of female arrival as demonstrated by the start of laying (Table 2). Clutches started in the latter half of June may partly belong to secondary females of bigynous males. Second or replacement clutches were never established in my boxes.

Nest-building took on average 6 days at 88 closely studied nests and egg laying started 2.7 days after nest completion (mean for 348 nests). An interval of 1-4 days was most common (73\%) but was sometimes as much as 9-14 days (8\%).

\section{Clutch size}

The fluctuations in mean clutch size during the study period are shown in Figure 4. The mean clutch in each season and the percentage of clutches in each clutch-size category are shown in Table 3 , together with those from four other studies in south and central Sweden. Clutch size varied considerably between years but showed no tendency to change over the two decades of study. The wellknown so called calendar effect was clearly manifested; clutch size decreased significantly with the progress of the season (Figure 5).

The size of all 1009 complete clutches varied from 3 to 11 eggs, with 6 and 7 eggs as the most numbers. More than one female had probably contributed to clutches larger than 8 eggs. The populations in central Sweden had a larger proportion of 6-egg clutches and fewer small clutches than the south Swedish ones (Table 3), an enigmatic although highly significant difference $\left(\chi^{2}{ }_{24}=65.8\right.$. $\mathrm{p}<0.001$ ). 


\section{Breeding success}

All nests were monitored from egg laying until the fledging of the last chick. Nests sometimes suffered considerable predation and other disturbances. Productivity differed considerably between seasons, from less than three to more than five fledglings per started brood (Table 4). The overall mean of 4.27 fledglings per brood is significantly less than the 5.27 to 5.57 fledglings obtained in the abovementioned Swedish long-term studies. These also show higher values for other breeding parameters, such as proportion of hatched eggs (my percentage first, theirs in brackets) $84 \%$ (92\% to $97 \%$ ), proportion of fledglings of hatched eggs $81 \%(91 \%$ to $96 \%$ ), proportion of fledglings of eggs laid $68 \%$ $(86 \%$ to $91 \%)$. A rather heavy predation pressure and a relatively large proportion of unhatched eggs probably contributed to the rather low productivity in my study area. Other factors, such as weather conditions and habitat quality, may differ between the compared studies and were probably also involved.

\section{Breeding failures}

The collected data on breeding failures are presented in Table 5. The proportion of nests without losses of any kind was $40 \%$, a percentage that shows a continuous, weak but significant decrease thorughout the 20 years $(\mathrm{r}=-0.50, \mathrm{p}<0.05)$. This proportion is doubled to $80 \%$ when only one fledgling is required to consider a nest successful.

A total number of 487 eggs did not hatch, corresponding to $8 \%$ of all eggs laid. Some unhatched eggs were found on the nest rim. This phenomenon was described by Nilsson (2005) and was studied in detail by Lobato et al. (2006). Such ejection of eggs out of the nest cup occurred rarely. Only 24 nests with ejected eggs were found in my study, corresponding to 2.4 per 100 nests, which equals the frequency found by Lobato et al. (2.8 per 100 nests).

Thirty clutches were deserted and 29 clutches were robbed during the incubation period. Five females were found dead in their nests. Nest-box usurpation by Great Tits and Doormice Muscardinus avellanarius caused the remaining clutch losses.
Most losses occurred during the nestling period when Pine Martens Martes martes depredated whole or part of at least 40 broods. Periods of rainy and chilly weather forced some females to abandon their nestlings.

The general impression is that my nest-box population was exposed to an unusually heavy predation pressure that explains the relatively poor breeding results. Red Squirrels Sciurus vulgaris and weasels Mustela nivalis may have contributed to the losses as did the occasionally frequent invasion of the boxes by nest-building bumble-bees and wasps.

\section{Ringing, controls, return rates}

Females and nestlings were ringed yearly with the exceptions of the seasons 1996 to 1999 when only returning ringed birds were trapped and checked. During the 16 "ringing" seasons, 838 clutches gave rise to 4395 hatchlings. I ringed 638 incubating females (76\%) and 3653 nestlings (83\%).

Only seven females ringed as nestlings returned to my boxes and four to other nest-box areas in the province $(0.3 \%)$, whereas 88 females ringed as adults returned $(16 \%)$, often to the nest-box group where they bred in the preceding season (28 individuals). Six females were trapped and controlled in nest-box groups about $20-60 \mathrm{~km}$ away from my area. The yearly number of ringed and returning females is presented in Table 6 . The average proportion of females returning one year after ringing was $12 \%$ (Table 7 ). This return rate is within the range of 10 to $15 \%$ that long ago was found to apply to flycatcher populations in central Sweden and southern Finland (Enemar 1948, von Haartman 1949). This means that only part of the surviving and returning females are site-tenacious, i.e. appearing in the nest-box area of the preceding year to breed, sometimes in the same box ( 7 cases).

Table 7 shows the return rates of surviving females together with figures obtained in central Sweden and southern Finland. It is apparent that the return rate increases to about 40 to $50 \%$ among females that have already returned once. This percentage coincides with the known survival rate of the species. The conclusion is that those females that have returned for a second time to their first breeding site continue to do so throughout their lifetime. 